\section{LA CONSULTA INDÍGENA EN CHILE: ¿DERECHO DE PARTICIPACIÓN $O$ DE LIBRE DETERMINACIÓN?}

\author{
INDIGENOUS CONSULTATION IN CHILE: RIGHT \\ OF PARTICIPATION OR SELF-DETERMINATION?
}

\section{ARNULF BECKER LORCA ·}

Investigador independiente, Escuela de Derecho Pontificia Universidad Católica de Valparaíso (Chile)

email: abeckerlorca@law.harvard.edu

\author{
AMAYA ALVEZ MARIN • \\ Profesora Asociada, Facultad de Ciencias Jurídicas y \\ Sociales, Universidad de Concepción (Chile) \\ email: aalvez@udec.cl
}

\section{Resumen}

El derecho a la consulta indígena está atravesado por una contradicción entre dos paradigmas: uno decolonial y otro de derechos humanos. En las negociaciones que llevaron al establecimiento del estándar internacional de consulta, representantes de Estados y de pueblos originarios del Norte global invocaron estos estándares, respectivamente. En Chile se observa una dinámica distinta. La historia Mapuche y Rapa Nui explica la visión que miembros de estos pueblos tienen de la consulta como derecho que reconoce la soberanía indígena subyacente. Si bien el derecho internacional no otorga hoy a pueblos indígenas un derecho de libre determinación externo, mientras las autoridades chilenas evaden la implementación seria de la consulta, el Estado contribuye a transformar los derechos de participación del pueblo Mapuche, en derechos de libre determinación.

\section{Registro bibliográfico}

BECKER LORCA, ARNULF Y ALVEZ MARIN, AMAYA «La consulta indígena en Chile: ¿derecho de participación o de libre determinación?», en: ESTUDIOS SOCIALES, revista universitaria semestral, año XXX, n 59, Santa Fe, Argentina, Universidad Nacional del Litoral, julio-diciembre, 2020, pp. 89-111.

\section{Abstract}

The right of indigenous peoples to prior consultation is marked by a contradiction between two paradigms: a decolonial framework and a human rights framework. States and indigenous peoples from the Global North have invoked these paradigms, respectively during the negotiations that led to set the standard. In Chile we see a different dynamic. The Mapuche and Rapa Nui's history explain why these peoples see prior consultation as a right that recognizes their underlying indigenous sovereignty. However, contemporary international law does not grant indigenous peoples an external right to self-determination. When Chilean authorities continue to evade the implementation of prior consultation as participation, the State might be giving the Mapuche people no other option than to claim external self-determination.

\section{Descriptores · Describers}

consulta indígena / libre determinación mapuche / derecho internacional de los pueblos indígenas

right to prior consultation of indigenous peoples / mapuche self-determination / international law of indigenous peoples

Recibido: 05 / 01 / 2020 Aprobado: 27 / 06 / 2020 


\section{INTRODUCCIÓN ${ }^{1}$}

El Convenio I69 de la Organización Internacional del Trabajo (оIт) reconoce a los pueblos indígenas el derecho a la consulta previa. ¿Cuál es la naturaleza de este derecho? ¿Qué significa que el Estado chileno tenga la obligación de consultar a los pueblos indígenas en el proceso de toma de decisiones que los afecten directamente? ¿Es la consulta un derecho que garantiza la participación en el proceso democrático de sectores tradicionalmente excluidos en Chile, o es la consulta una expresión más profunda del derecho a la autodeterminación indígena?

A una década de la vigencia del Convenio I69 en Chile, los contornos del derecho a consulta han sido definidos por un marco regulatorio destinado a reglamentar el cumplimiento de este derecho en general, así como específicamente en materia de evaluación ambiental (MEZA-LOPEHANDÍA, 2OI6; GUERRA-SCHLEEF, 20I7 $)^{2}$. Dicho marco regulatorio ha sido sujeto a examen judicial en una serie de decisiones, lo que ha originado una jurisprudencia que determina los contornos específicos del derecho a consulta previa, a veces expandiendo, otras veces restringiendo su alcance ${ }^{3}$. A diez años de la entrada en vigor del Convenio i69 de la oIt en Chile, académicos y estudiosos del derecho de los pueblos indígenas han examinado profunda y críticamente los obstáculos y falencias que ha experimentado la implementación de la consulta en Chile (SANHUEZA, 2OI3; NUÑEZ, 2OI4; MEZALopeHANDíA, 20I8). Estos estudios en general identifican la naturaleza, propósito y alcance del estándar internacional consagrado en el Convenio I69, interpretado

1] Este artículo es el resultado del trabajo realizado como coinvestigadora del Proyecto Fondecyt $\mathrm{N}^{\circ}$ 1151158 «El Régimen de Derechos Indígenas y el Estado Chileno: escenarios futuros»; y del Proyecto Fondap/Conicyt/15130015 del cual la Dra. Amaya Alvez es investigadora asociada. Agradecemos el trabajo efectuado por José Ramírez Gaete y Nicolás Díaz Carillo como ayudantes de investigación. También agradecemos los comentarios formulados por el Editor invitado Juan Pablo Scarfi y por los árbitros ciegos de la Revista Estudios Sociales. Todo error es nuestra sola responsabilidad.

2] Convenio de 1989 , publicado en Chile el 14 de octubre de 2008 y en vigencia desde el 15 de septiembre de 2009.

3] En algunos casos expandiendo los contornos de la consulta, desde un mecanismo para informar a las comunidades a un mecanismo de participación y hasta obtención de acuerdo por parte de las comunidades indígenas, en el ámbito de impacto ambiental, por ejemplo. En otros casos, confirmando los límites de la consulta, excluyendo a dirigentes tradicionales o imponiendo lo consultado sin pertinencia cultural. Un ejemplo de esto está es la consulta indígena referente a la subdivisión de la tierra comunal indígena. 
a la luz de la Declaración de Naciones Unidas sobre Pueblos Indígenas $(2007)^{4}$ y otros documentos legales blandos como los informes de Relatores Especiales, así como a la luz de la jurisprudencia regional e internacional, para luego comparar el estándar internacional con la implementación del derecho y cumplimiento de la obligación de consulta por el Estado chileno.

Estos estudios son fundamentales para determinar si los derechos que el orden legal internacional reconoce a los pueblos indígenas son respetados en Chile. En virtud de estos objetivos, dichos estudios ofrecen una interpretación, sino expansiva, unívoca del estándar internacional. Textos, contextos y jurisprudencia ofrecen un estándar claro: en relación con el surgimiento de la obligación de consultar, a las condiciones de un proceso de consulta conducido de buena fe, al significado de "afectación directa», a la obligación de acomodación y respeto de otros derechos ante el evento de falta de acuerdo, entre otros.

En este artículo no pretendemos dilucidar el cumplimiento o incumplimiento del estándar internacional, puesto que, en vez de identificar un contenido esencial, o un contenido que evoluciona armónicamente en el tiempo reaccionando a demandas sociales, vemos el estándar internacional de la consulta indígena como norma que presenta tensiones y contradicciones. El derecho a la consulta en sí, como argumentaremos, se encuentra atravesado en su origen por visiones políticas contrapuestas de la comunidad internacional. Esta tensión se produce por la coexistencia de al menos dos paradigmas dentro de esta norma internacional: uno decolonial, basado en la libre determinación de los pueblos originarios, y otro de protección de derechos humanos (DD.HH.), que sostiene la participación ciudadana de los pueblos indígenas como la de un grupo inserto en una comunidad política que ejerce derechos como cualquier otro grupo minoritario (KENNEDY, I987; ENGLE, 2OIO; ERUETI, 2OI6).

Desde el punto de vista de los DD.HH., construir un estándar unívoco, y abogar por su cumplimiento, es más importante que descifrar potenciales contradicciones. Sin embargo, este artículo examina las contradicciones a fin de identificar los límites de la consulta, con la convicción que existe un espacio de conflicto sobre la naturaleza y alcance de este derecho, que no se agota con una mejor implementación del estándar. Tenemos esta convicción porque después de una década, y a pesar de que Chile cuenta con reglamentación administrativa, con experiencia en consultas y con

4] Adoptada en Nueva York el 13 de septiembre de 2007, con el voto favorable de Chile. 
jurisprudencia respecto de controversias relativas al derecho a consulta previa, esta experiencia ha dejado a muchos — en las comunidades indígenas, de académicos y activistas y a representantes del Estado- insatisfechos (CASTRO, 2OI8).

La consulta indígena, en estos diez años ha ganado un espacio central en la relación entre Estado chileno y pueblos indígenas, convirtiéndose en herramienta de respeto de derechos indígenas y espacio de interacción política entre estos pueblos y el Estado chileno. Argumentamos que la insatisfacción con la consulta proviene del conflicto entre paradigmas. Para el Estado y gran parte de la sociedad chilena, un proceso de consulta de buena fe y conducido respetando garantías procedimentales cumple con el estándar de DD.HH. En cambio, los pueblos indígenas en territorio chileno, y en especial la intelectualidad Mapuche, observan la consulta a través del paradigma decolonial, observan así una herramienta inadecuada mientras no reconozca la soberanía subyacente de los pueblos originarios.

Contrastaremos la visión de un estándar internacional unívoco, claro y fuerte con una trayectoria que ilustra las tensiones y contradicciones, es decir, el surgimiento del derecho de consulta como compromiso entre el paradigma decolonial y de derechos humanos o participación. Concluimos mostrando que en el marco chileno conviven ambos paradigmas y argumentando que conviene identificar esa cohabitación a fin de repensar los derechos de los pueblos originarios en Chile.

\section{DERECHO INTERNACIONAL Y PUEBLOS INDÍGENAS}

La consulta previa, es un derecho de los pueblos indígenas y una obligación internacional que tienen los Estados que, como Chile, han ratificado el Convenio OIT I69. Junto con la Declaración sobre los Derechos de los Pueblos Indígenas (2007), el derecho internacional ofrece garantías para que derechos básicos, de grupos definidos como pueblo indígena y de individuos formando parte de dichos grupos, sean respetados por el Estado que ejerce jurisdicción sobre el territorio donde éstos se encuentran.

La consulta es uno de los derechos incluidos en el Convenio y la Declaración, que como veremos, fue concebida no como documento que otorga nuevos derechos, sino como documento que aclara derechos preexistentes, que indígenas gozan como sujetos de DD.HH. y del derecho internacional general. La naturaleza y el alcance de la consulta depende entonces no sólo de una interpretación de 
este derecho en particular, en el Convenio i69 y en la Declaración del 2007, sino también de una interpretación del derecho internacional en general como límite al ejercicio de la soberanía de los Estados. Académicos y activistas con posturas afines a los pueblos indígenas, construyen la consulta previa como un derecho de contenido amplio, con requisitos y con un alcance bien delimitado (vid. CARMONA, 2OI3; MORRIS, RODRÍGUEZ, ORDUZ Y BURITICÁ, 2009).

Esta interpretación, pensamos, adquiere coherencia si uno mira la consulta como un derecho que forma parte de la libre determinación de los pueblos indígenas, acercándose, por lo tanto, a un derecho de veto a ciertos impactos, como es el caso del reasentamiento, y en caso de inobservancia, dejando a dichos pueblos con facultades de invocar derechos subyacentes a la soberanía estatal, como derechos análogos a los que detenta un pueblo soberano (MILLALEN, 20I3). Estas interpretaciones se contraponen al contenido y alcance de la consulta previa en tanto interpretada por los tribunales chilenos. La jurisprudencia chilena, quizás menos unívoca que los organismos no gubernamentales, refleja igualmente una interpretación coherente de la consulta, no como derecho de libre determinación, sino como derecho de participación en los procesos de decisión gubernamental que afectan los intereses de los pueblos indígenas, con ello, un paradigma de participación da coherencia a interpretaciones que enfatizan los procesos de toma de decisión y de participación, y no necesariamente los resultados. ${ }^{5}$

¿Cuál de estos dos paradigmas debiera prevalecer en la interpretación del derecho a consulta? En esta sección exploramos brevemente la historia de la relación entre derecho internacional y pueblos indígenas a fin de contextualizar ambos paradigmas. Pudiera pensarse que durante las negociaciones que desembocaron en el Convenio I69 y en la Declaración de Naciones Unidas, pueblos indígenas invocaban la libre determinación, mientras los Estados defendían el paradigma de DD.HH. Sin embargo, siguiendo la literatura predominante, mostraremos que, du-

5] Así por ejemplo en el caso Parlamento Rapa Nui y otros / Estado de Chile, Ministerio de Bienes Nacionales y Corporación Nacional Forestal. En primera instancia Corte de Apelaciones de Santiago, Rol № 89686-2015, Sentencia de fecha 08/01/2016 y en segunda la Corte Suprema, Rol № 4238-2016, Sentencia de fecha 01/08/2016. El acto recurrido es la Res. №383-2015, 09/09/2015, que modificó la Res. №344-2015, del 26/08/2016 que «convoca a un proceso de consulta sobre el proceso de cogestión del Parque Nacional Rapa Nui, con el objeto de materializar un proceso de coadministración». La Corte Suprema señala: El Estado debe asegurar la efectiva participación de los grupos étnicos en las decisiones que les conciernen (considerando $11^{\circ}$ ). 
rante las negociaciones, tanto representantes de distintos Estados como de distintos pueblos indígenas invocaron ambos paradigmas. La distinción relevante, por ello, no fue entre Estados y pueblos indígenas, sino las diferentes experiencias históricas entre Estados y pueblos indígenas del Norte y del Sur global: Representantes de Estados y pueblos del Norte concibieron la consulta como dimensión del derecho de autodeterminación y Estados y pueblos del Sur concibieron la consulta como derecho de participación (ENGLE, 2OIO; ERUETI, 2OI6).

Como parte del sur global, el Estado de Chile y pueblos originarios que cohabitan el respectivo territorio, deberían haber concebido la consulta como un derecho de participación, una especie de derecho civil y político especial, reconocido a los pueblos indígenas en virtud de sus peculiaridades, pero como parte del pueblo chileno sujeto del derecho de libre determinación. Sin embargo, una breve exploración histórica servirá para corregir en parte esta narrativa en relación al pueblo Mapuche (Ngulu Mapu), y por tanto, en relación a Chile.

En otra investigación, hemos examinado la historia entre derecho internacional y pueblos indígenas, desde las independencias latinoamericanas a comienzos del siglo XIX hasta nuestros días (BECKER Y ALVEZ). Dicha investigación pone en tela de juicio la idea que el derecho internacional ha sido una fuerza virtuosa para los pueblos indígenas. Los paradigmas que interpretan la consulta como parte de la libre determinación o de la participación asumen que el derecho internacional ha sido en general una herramienta, que, como los derechos humanos, limita y así domestica la soberanía estatal. Mostramos a continuación lo contrario: los pueblos indígenas, como sujeto de derecho, no han calzado bien, ni en el régimen internacional de soberanía estatal, (libre determinación), ni en la protección de minorías, y sólo parcialmente en el régimen de DD.HH. (participación). Esto no significa que los pueblos originarios estén eternamente condenados por regímenes legales que no reconocen sus intereses. Que los pueblos originarios y sus demandas no calcen en los regímenes internacionales existentes impone costos, pero no cortapisas irremontables a la capacidad de estos pueblos para usar el régimen de derechos humanos, el Convenio oiT, o el derecho internacional de libre determinación, en la prosecución de sus intereses y demandas. Por lo tanto, exploramos acá dichos costos dejando constancia de la capacidad de resistencia indígena por medio del derecho internacional. Entre muchos otros ejemplos, nótese que el Consejo de 
Coordinación de la Nacionalidad Waorani Ecuador Pastaza (CONCONAweP) obtuvo de una corte de Pastanza una acción de protección ${ }^{6}$ en contra de un proyecto petrolero por vulneración del derecho de consulta (MORRIS ET. AL., 2009).

\section{La consulta previa como herramienta de participación}

La Declaración de Naciones Unidas sobre Derechos Indígenas, adoptada en 2007, culminó un proceso de al menos dos décadas de negociaciones, durante las cuales líderes del movimiento indígena y activistas, transitaron en la articulación de sus tradicionales demandas hacia un modelo de DD.HH. (BARELLI, 2OI6). Este último modelo parecía útil, no sólo conceptualmente —en cuanto límites al ejercicio de la soberanía — sino también políticamente para el cumplimiento de las demandas indígenas. Este modelo reflejaba desplazamientos tectónicos en la confrontación ideológica global, emergiendo como principal ideología en un mundo supuestamente posideológico tras el fin de la Guerra Fría (MOYN, 20I2).

En uno de los más influyentes estudios sobre pueblos indígenas en el derecho internacional, James Anaya afirma que el positivismo de un derecho internacional «estado-céntrico» dio paso a fines del siglo xx, a un derecho reformado, que en los DD.HH. reconoce mayor consideración a individuos y grupos, y que en el diseño de un orden mundial pacífico y justo reconoce la relevancia de consideraciones morales (ANAYA, 2004: 49). Esta transformación es para Anaya fundamental, puesto que devolvió al derecho internacional el carácter universal y moral que había perdido en el siglo XIX a manos del positivismo jurídico (ANAYA, 2004: 50).

Sin embargo, Anaya observa que la transformación no fue absoluta. En la «igualdad soberana» y en la «integridad territorial», el orden legal internacional de la posguerra dejó al estatismo importantes espacios, pero espacios de acción que serán contrarrestados con los «preceptos humanistas y objetivos morales» que permean el derecho internacional contemporáneo (ANAYA, 2004: 52). Es decir, para los pueblos indígenas, no es la autodeterminación, sino los DD.HH. los que operarán en el orden internacional del siglo Xxi como contrapeso de la soberanía. Contrapeso que otorgando subjetividad internacional a sujetos no-estatales marca el retorno del pensamiento de derecho natural. No obstante, siendo el mismo

6] Sobre la acción de protección obtenida por el Pueblo Waorani, ver https://www.amazonfrontlines. org/chronicles/victoria-waorani/ (último ingreso: 06/01/2020) 
pensamiento que teólogos y juristas usaron para someter a los pueblos indígenas en el siglo XVI, esta vez, Anaya sostiene, otorgar personalidad a sujetos no estatales ocurre «libre de las ataduras eurocéntricas» del pasado (ANAYA, 2004: 53). Y así, esta apertura creada por los DD.HH. ha servido como base para que el derecho internacional revisite su tratamiento de los pueblos indígenas, esta vez con la capacidad de ponerse al servicio de sus aspiraciones (ANAYA, 2004: 53).

En el año 2008, como Relator Especial sobre la situación de los DD.HH. y las libertades fundamentales de los indígenas, Anaya participó en esta transición hacia un derecho internacional al servicio de las aspiraciones de los pueblos indígenas. En su primer informe al Consejo de Derechos Humanos de Naciones Unidas, Anaya interpreta la Declaración del 2007 como articulando el «contenido mínimo de los derechos de los pueblos indígenas» fundados en las normas internacionales de DD.HH. (ANAYA, 2008: para. 85) Es decir, no se trata de conferir nuevos derechos especiales, sino aplicar normas existentes de derechos humanos a «las circunstancias concretas históricas, culturales y sociales de los pueblos indígenas» (ANAYA, 2008: para. 86). Es decir, Anaya concibe la Declaración como un instrumento «reparatorio» respecto de las injusticias históricas sufridas por los pueblos indígenas, remediando específicamente las consecuencias de la denegación del derecho a la libre determinación, así como de otros derechos humanos fundamentales (ANAYA, 2008, para. 36).

Si bien los DD.HH. ofrecen una oportunidad de reparación histórica, para Anaya es claro que dicha oportunidad es consecuencia de la denegación de otras avenidas de rectificación por parte del derecho internacional, principalmente la denegación del derecho de autodeterminación (ANAYA, 2004: 54). Tanto en la independencia Hispanoamericana el siglo XIX, como en la descolonización de los años 6o, la libre determinación de los pueblos eludió la autonomía de los órdenes políticos indígenas, a favor, según la doctrina estadocéntrica del uti possedetis, de las entidades territoriales formadas durante el período colonial. Por lo tanto, desde la perspectiva de Anaya, tiene sentido aprovechar la avenida alternativa, paralela a la descolonización, que los DD.HH. ofreció a los pueblos indígenas, especialmente al abrir las puertas a líderes y representantes indígenas, quienes accediendo directamente al escenario internacional formularon demandas fundadas en ellos (ANAYA, 2004: 56-57; DAES, 1996).

La ONU auspició el diálogo con pueblos indígenas, en la Conferencia Internacional de ongs sobre la Discriminación contra los Pueblos Indígenas de las Américas, realizada en septiembre de 1977, y con en el trabajo pionero de José 
Martínez Cobo y su informe relativo a la discriminación sufrida por los pueblos indígenas en el sistema internacional (E/CN. 4/2004/80). La Conferencia de 1977 desencadenó un proceso de negociaciones diplomáticas en las cuales la participación directa de representantes de los pueblos indígenas como el dirigente Mapuche Nilo Cayuqueo o Juan Navarro Kolla, representantes de la Asociación Indígena de la República Argentina AIRA, contribuyó al reemplazo del marco asimilacionista de los pueblos indígenas, que había sido establecido por el Convenio io7 de la OIT, por un marco de derechos indígenas independiente, en el Convenio orT I69 de 1989, proceso que culminó más de una década después en la Declaración de Naciones Unidas de Derechos Indígenas el ańo 2007.

En esta trayectoria, nuevamente aquellos que han planteado que los DD.HH. constituyen una vía alternativa ante la denegación de otras opciones parecen tener la razón. Durante las negociaciones que llevaron a la firma del Convenio i69, representantes de varios Estados, y en particular, representantes latinoamericanos se opusieron específicamente al reconocimiento de la autodeterminación indígena. Durante la última discusión previa a la aprobación del articulado del Convenio, el representante del Secretario General de la OIT reiteró «el cambio radical» en las actitudes hacia indígenas que había inspirado la revisión del régimen vigente hasta ese entonces. En víspera de las negociaciones finales, el representante destacó el consenso logrado en torno a la sustitución del espíritu asimilacionista del Convenio I07, por una política de «respeto a la identidad y culturas» indígenas, y en torno a la incorporación de éstos en la toma de decisiones que los afecten (ILO, 1989: 25/I, para. 6).

Así, la política de asimilación e integración de pueblos indígenas fue reemplazada por una política de diferenciación, confiriendo derechos a la identidad, cultura y participación. El reemplazo de la asimilación por la de diferenciación excluyó una política de autonomía indígena. El representante de la oit explicaba que no se había obtenido consenso respecto de la sustitución del término «población» aun cuando «ambas partes están de acuerdo que el separatismo político» que pudiera sobrentenderse en el término "pueblo», «deber ser de ninguna manera promovido por el Convenio» (ILO, 1989: 25/I, para. 6).

Ambas partes — recordemos la estructura tripartita de la OIT- refiere aquí a representantes de gobiernos y de empleadores. Estos últimos manifestaron «serias reservas» al uso del término, y a trabajadores y algunos gobiernos apoyando el uso del término pueblo. Entre los gobiernos más firmes en su oposición, se encontraban 
los latinoamericanos, Argentina y Venezuela advirtiendo la necesidad de «evitar erróneas interpretaciones en el contexto de la autodeterminación bajo el derecho internacional»; y Nicaragua declarando que pueblo no implica el «reconocimiento de un Estado dentro del Estado» (ILO, 1989: para. I3). Aprehensiones similares a la relación entre pueblo y el derecho de autodeterminación, fueron manifestadas por los delegados de Argentina y Perú (ILO, I989: 25/8, para. I3). Que representantes de gobiernos latinoamericanos se manifestaran contrarios a la autodeterminación no sorprende. En cambio, es interesante constatar que la postura de representantes de agrupaciones indígenas en la conferencia no fue muy diferente.

Representantes de pueblos indígenas de la región, como el Coordinador de las organizaciones indígenas de la cuenca Amazónica y el representante del Consejo de Indios de Sudamérica, apoyaron la inclusión del término «pueblo» en el artículo primero del Convenio. La inclusión del término pueblo, reflejaría la existencia desde los tiempos que preceden la colonización, de grupos con lengua, tradiciones propias. Sin embargo, el representante de los pueblos amazónico se ve además en la necesidad de clarificar que la utilización del término pueblo no expresa el «deseo de crear un estado dentro del estado... [estos] son verdaderamente parte del país donde pertenecen y han demostrado ampliamente que no han ni emprenderán acciones destinadas a la autodeterminación» (ILO, I989, 25/6 para. 27). El representante del Consejo, a su vez, argumentaba que la necesidad de autodeterminación se enmarcaba en el problema de la discriminación y del respeto a los derechos humanos, como el acceso a los recursos naturales indispensables para la subsistencia (ILO, 1989, 25/6 para. 28).

Acá no se trata de juzgar posiciones en abstracto, pues el espacio de maniobra para los pueblos indígenas era reducido. Si representantes de gobiernos y de pueblos indígenas lograron consensuar el reemplazo del paradigma asimilacionista del Convenio I07, pocas eran las posibilidades de empujar, en aquel momento, las demandas allende el paradigma de DD.HH. que a fines de los años I980 ya se había consolidado. La demanda de autodeterminación, más propia de la descolonización de los años 1960 que del discurso de los DD.HH., ante la oposición explícita de representantes de gobiernos, no tenía en ese entonces futuro alguno. Por otra parte, el reconocimiento a nivel internacional de derechos a la diferencia, principalmente a la diferencia cultural, fueron en ese momento una conquista para los pueblos indígenas y una novedad en la región. 


\section{Consulta después de la Declaración de Naciones Unidas:}

\section{¿ejercicio de autodeterminación?}

El derecho a la libre determinación, desde fines de la década de los sesenta, quedó bien establecido como agente descolonizador. Previamente, había quedado establecido por el derecho internacional que pueblos indígenas no constituían un "pueblo» para efectos del ejercicio de la autodeterminación en su faceta externa. Ahora bien, como parte de la población de un Estado independiente, sí eran sujetos de autodeterminación en su faceta interna. En la fórmula de los Pactos de DD.HH., pueblos indígenas tienen derecho a establecer libremente su condición política y proveer su desarrollo económico, social y cultural. Sin embargo, la línea divisoria entre las facetas interna y externa no es ni absoluta ni estable. Por tanto, cuando la autodeterminación reaparece en las negociaciones conducentes a la Declaración de Pueblos Indígenas del 2007, surge nuevamente la pregunta sobre el alcance y reconocimiento del derecho a la libre determinación.

Cuando el Grupo de Trabajo sobre Pueblos Indígenas comenzó a reunirse a fin de discutir la redacción de la Declaración a comienzo de los años ochenta, la cuestión sobre la libre determinación estaba al centro de las preocupaciones de delegados y activistas indígenas. Pero mientras había entre ellos consenso sobre la inclusión de este derecho, no lo había sobre su alcance (ENGLE, 20IO: 67). La inclusión de la autodeterminación en la Declaración — de acuerdo con Anayano significaba, ni para los Estados, ni para los propios pueblos indígenas, una aspiración a la independencia (ANAYA, 2004b: 195). De modo similar, Rodolfo Stavenhagen, notaba unos años después de la adopción de la Declaración que, el consenso general, concebía el derecho a libre determinación de los pueblos indígenas en su dimensión interna, como autonomía doméstica. Sin embargo, notaba también que el consenso no fue «siempre compartido por las organizaciones indígenas» (stavenhagen, 20II: 4I4-42I). Por ello, académicos más críticos han argumentado que el espíritu descolonizador del derecho internacional de los años sesenta se mantuvo vivo y resurgió con fuerza en las demandas del movimiento indígena de la década de los ochenta y noventa (ENGLe, 2OIO).

La articulación de fuerzas que desembocó en la Declaración de Naciones Unidas resultó en parte de la formación de ONG indígenas y de la alianza de éstas con ONG no-indígenas, que desde los años setenta en adelante conformaron un movimiento indígena transnacional que logró empujar la agenda y participar en las negociaciones ante la Comisión de DD.HH. y comités especiales de Naciones 
Unidas. Por ejemplo, una de las primeras ONG indígenas, la International Treaty Council, fundada en Estados Unidos en 1974, y el Consejo Indio de Sudamérica, fundado en Perú en 1980 y reuniendo diferentes organizaciones de Latinoamérica, participaron en el largo proceso de negociación. La primera presentó una declaración modelo que perseguía la libre determinación en tanto independencia, y la segunda siendo la única organización del sur global y de Latinoamérica que participó en las primeras sesiones del Grupo de trabajo (LÂM, 2000: 34-36) ${ }^{7}$. En consecuencia, que Naciones Unidas, más allá de la OIT, se convirtiera en escenario para abordar la problemática indígena no se entiende sin la participación del movimiento indígena transnacional.

En 1971, la Subcomisión de Prevención de Discriminaciones y Protección a las Minorías recomendó a la Comisión de DD.HH. el estudio de la discriminación que sufrían los pueblos indígenas, nombrando al diplomático y jurista ecuatoriano José Martínez Cobo como relator especial, quien elaboró durante la década de los ochenta una serie de informes que sugerían que los instrumentos internacionales, principalmente los DD.HH. universales existentes hasta ese entonces eran inadecuados para resistir la asimilación y para proteger la diferencia cultural (MARTINEZ сово, 1983). Por ende, en su reporte final, el relator propone la libre determinación política y la necesidad de un instrumento legal internacional específico como una Declaración, entre otras soluciones a la problemática indígena (MARTINEZ COBO, 1986). A medida que los informes de Martínez Cobo salían a la luz y la presión del movimiento transnacional aumentaba, la Comisión de DD.HH. respondía creando en 1982 el Grupo de Trabajo sobre Pueblos Indígenas, conformado por expertos independientes, y encargado de establecer estándares para regular y monitorear la relación entre Estados y pueblos indígenas (LÂM, 2000; BELLIER, 20IO: 4I-7I).

Para algunos la demanda central del movimiento indígena durante las negociaciones era la autodeterminación (WILliams, 1990: 660). Sin embargo, todo dependía del sentido y alcance que activistas daban a dicha demanda. En su estudio sobre la libre determinación indígena, Lâm, por ejemplo, estima que la demanda

7] Entre las ONG formadas por no-indígenas, se contaba la International Working Group for Indigenous Affairs, fundada por antropólogos en 1968. Para la declaración modelo, véase, Information Received from Non-Governmental Organizations, International Indian Treaty Council, Draft Principles for Guiding Deliberations of the Working Group, UN Doc E/CN.4/ Sub.2/AC.4/1983/5/Add.2 (1983). Sobre la participación del Consejo Indio de Sudamérica CISA véase (ERUETI, 2016: 50) 
de libre determinación era principalmente perseguida por grupos indígenas de habla inglesa, mientras delegaciones provenientes de Asia, sin rechazar la demanda, intentaban evadir el término enfocándose por el contrario en la batalla contra de la discriminación y el genocidio (LÂM, 2000: 54 y ss.) En Latinoamérica, por ejemplo, la Declaración de Quito, firmada en 1990 concluyendo el Primer Encuentro Continental de Pueblos Indios, muestra la ambivalencia de las organizaciones de la región respecto de cuál de las facetas de la demanda de libre determinación debiera ser privilegiada, la faceta externa o interna, autodeterminación como independencia o autonomía. El encuentro de pueblos del 90 reafirma la lucha indígena, pero no como respuesta a la contingencia del cincuentenario de la conquista, sino como respuesta a la toma de conciencia que la liberación definitiva puede sólo resultar del «pleno ejercicio de nuestra autodeterminación». Sin embargo, afirmando la unidad entre pueblos sobre la base de este «derecho fundamental», la declaración aclara que la libre determinación se expresa como «plena autonomía (...) en el marco de los Estados Nacionales» ${ }^{8}$.

Durante las negociaciones de fines de los ochenta y noventa, las tensiones entre la libre determinación como demanda esencial del paradigma descolonizador de los años sesenta y la demanda de autonomía como parte del discurso de DD.HH. de los noventa, fueron resueltas en favor de éstos últimos, en desmedro del paradigma descolonizador. Esta es la hipótesis central del estudio de Karen Engle. En su libro pone de relieve los límites que los DD.HH., específicamente el marco de derechos culturales, imponían a activistas indígenas. Al mismo tiempo que el neoliberalismo se consolidaba, el paradigma de derechos culturales desarticulaba las preocupaciones que habían inspirado el activismo indígena: la dependencia económica, la discriminación, la autonomía. De esta suerte, el ascenso de derechos culturales ha traído consigo la disminución de las oportunidades de demandar desarrollo y autonomía indígena (ENGLE, 2OIO: I-2).

No sólo Lâm y Engle, otros comentaristas también, como Xanthaki y Erueti, han identificado la transición desde la descolonización a los derechos humanos (XANTHAKI, 2OIO: I32; ERUeTI, 20I6). Sin embargo, el académico maorí Andrew Erueti enfatiza el compromiso que organizaciones del sur global expresaban respecto de los DD.HH. desde el comienzo de las negociaciones. La mayoría de los

8] Véase, Encuentro Continental de Pueblos Indígenas, 1990. Declaración de Quito y resolución del Encuentro Continental de Pueblos Indígenas: Quito, 17-21 de julio de 1990, Quito. 
comentaristas afirman que el marco de referencia descolonizador era el marco dominante al tiempo de iniciadas las negociaciones encaminadas a la Declaración del 2007. Para activistas del norte global y para los pueblos indígenas de las excolonias británicas, un derecho grupal de libre determinación era la alternativa preferida (ERUETI, 20I7: 57I-573; 20I6; ENGLE, 20IO: 7I, 73-8I). Como explica Erueti, la experiencia de los pueblos indígenas del norte global, como pueblos originarios - first peoples — que regularon las relaciones con los occidentales a través de tratados, concibiéndose como naciones independientes, implicó que demandaran en las negociaciones la libre determinación como derecho a independencia política. Estos pueblos perseguían así la recuperación del poder político propio de una nación y por ello, la restauración de las que fueron históricamente sus instituciones y territorio (ERUETI, 20I7: 572-58I; 20I6: 50) .

Por el contrario, en Latinoamérica, hubo varias razones para que no sólo diplomáticos, sino también organizaciones indígenas de la región concordaran entorno a una estrategia centrada en el marco de derechos humanos. Por una parte, los Estados latinoamericanos han tendido a ser reacios a limitar su soberanía reconociendo a indígenas el carácter de pueblo. Por otra parte, los pueblos indígenas de Latinoamérica, a diferencia de los pueblos del norte, no pudiendo demandar libre determinación sobre la base de tratados firmados con potencias coloniales — sin perjuicio de las excepciones que veremos más adelante— se inclinaban más a formular demandas de diferencia cultural en el marco de los derechos humanos (ENGLE, 2OIO: 63; ERUETI, 20I7: 580). En particular, Engle sugiere que las tradicionales políticas indigenistas asimilacionistas de los Estados fueron, desde los años ochenta y noventa, contrarrestadas por un pan-indianismo que no obstante rechazando la hegemonía del pensamiento occidental a fin de recuperar el pensamiento propio, no articulaba frontalmente una demanda soberana secesionista (ENGLE, 20I0: 55-56, 63). Es así como donde la población indígena es mayoritaria, como en Bolivia y Guatemala, no tenía sentido demandar secesión, sino que organizaciones indígenas perseguían el control del Estado como expresión de la soberanía popular de corte indianista, como lo es caso del movimiento katarista boliviano (ENGLE, 20IO: 63-66, 8I; ESCÁRZAGA, 20I2: I85-2IO). En cambio, en países donde

9] Argumentando que organizaciones del CANZUS (esto es el grupo negociador conformado por Canadá, Australia, Nueva Zelandia y Estados Unidos) eran mayoritarias. CISA era la única organización fuera del norte global y de Latinoamérica presente en las negociaciones. 
la población indígena era minoritaria, aun cuando significativa, organizaciones indígenas buscaban la autonomía, en tanto derecho a la diferencia cultural y al control territorial dentro del marco estado-nacional.

Ya sea por estas razones de fondo, o como estrategia, en tiempos que impulsar demandas más radicales frente a regímenes autoritarios significaba exponerse a la brutal represión estatal, las organizaciones indígenas de Latinoamérica privilegiaron el paradigma de los derechos humanos. Y aquí cabe recordar el rol que las organizaciones de DD.HH. y la institucionalidad regional, la Comisión y Corte Interamericana de Derechos Humanos (CIDH), ocuparon en la transición y consolidación de las democracias latinoamericanas, lo cual ciertamente contribuyó a que la fortaleza del paradigma de derechos se proyectase al ámbito indígena. Es así como el sistema interamericano de DD.HH., junto a la supervisión internacional, surgieron como aliados principales de la causa indígena, aliados que situaban la consulta al centro del régimen de derechos indígena (SAUL, 20I6).

Esta preferencia de los pueblos originarios de la región coincidió con el debilitamiento de la demanda de libre determinación durante las negociaciones de la declaración. El paradigma descolonizador, que predominó la discusión desde la instalación del Grupo de Trabajo hasta la redacción del primer borrador aprobado en 1993, se fue debilitado entre 1994 y la firma de la Declaración en 2007. El paradigma descolonizador de aquel borrador significaba no sólo el reconocimiento de la libre determinación y la consulta previa, sino también referencias a la integridad territorial de los Estados, que como hemos visto, habiendo sido siempre incluidas en las declaraciones sobre autodeterminación, eran esta vez excluidas (ENGLE, 20IO: 73-8I). Como era de esperar, los Estados participantes en el proceso de negociación reaccionaron rápida y firmemente. Cuando el texto elaborado por los expertos del Grupo de Trabajo volvió a la Comisión de DD.HH. —que recordemos estaba conformada por delegados representando Estados miembros, a diferencia del Grupo de Trabajo conformado por expertos independientes—, la Comisión decidió establecer su propio y nuevo Grupo de Trabajo (ERUETI, 20I7: 582) ${ }^{10}$. Fue durante la labor del nuevo Grupo que se incluyó en el texto la referencia a la integridad territorial de los Estados, pero sin eliminar las referencias a la libre determinación.

10] Véase la decisión en Resolución 1995/32, en CN.4/1995/L.II/Add.2, 3 de marzo, 1995, p. 536. 
En consecuencia, el texto final, como sugiere Erueti, se lee como un texto híbrido. La cuestión del sentido y alcance de la libre determinación quedó sin resolución, pues ambos paradigmas conviven en el mismo documento. Mientras el Artículo 3 de la declaración proclama la libre determinación parafraseando los Pactos de DD.HH., el Artículo 4 especifica el ejercicio de este derecho como derecho a la autonomía sobre asuntos internos y locales, y por su parte el Artículo 46 contrapesa las disposiciones anteriores dejando en claro que la integridad territorial y la unidad política de los Estados soberanos limitan la faceta externa de la libre determinación (LÂM, 2000: 54-55; MACKLEM, 2015: I6I). En un texto legal híbrido, donde consideraciones divergentes sobre los valores y objetivos perseguidos por el derecho coexisten en conflicto, es habitual encontrar operadores legales en desacuerdo sobre la interpretación correcta. Usualmente, en estos casos, la interpretación dominante es producida no por el texto legal estricto, sino por el contexto político. Precisamente quienes consideran los DD.HH. como proyecto que aglutina visiones legítimas de la soberanía y del buen gobierno, tienden a leer la Declaración de Naciones Unidas y el Convenio 169 como documentos que reconocen la consulta como instrumento de participación. Esta ha sido, como Engle, Erueti y otros han sugerido, la interpretación dominante en Latinoamérica desde los años 9o, durante las negociaciones, hasta la firma del documento y en la práctica posterior a la firma, en que el activismo y demandas indígenas han estado centradas en la consulta previa como herramienta de resistencia, por ejemplo, frente a la industria extractiva.

Como instrumento vinculante, el Convenio 169 reconoce a pueblos indígenas el derecho a ser consultados. Para muchos comentaristas, ya que el Convenio incluye sólo implícitamente la libre determinación, la consulta abre un proceso de participación, que persigue obtener consentimiento de los pueblos por medidas que los afecten ${ }^{11}$. Sin embargo, interpretando el sentido y alcance de la consulta en el Convenio, nos encontramos con la Declaración empujando el significado de la consulta tanto como derecho a la participación, como derecho a la libre determinación. Tanto el trabajo de Engle como el de Erueti sugieren la supremacía del paradigma de los derechos culturales, como expresión de reconocimiento de DD.HH. respecto de los pueblos indígenas. Pero que los derechos humanos imperen sobre el paradigma de la autodeterminación, no se debe a la claridad de los textos

11] El Convenio OIT 169, en el preámbulo habla de las aspiraciones indígenas a controlar instituciones propias, formas de vida y desarrollo económico dentro del marco de los Estados en que se encuentran. 
legales, puesto que éstos consagran ambos paradigmas, sino más bien a la fuerza ideológica que los DD.HH. han desplegado en la región (ENGLE, 2OII: I4I-I63). Es así como la CIDH, se ha convertido en uno de los actores centrales en el avance de las demandas indígenas, reconociendo en su jurisprudencia derecho a la autonomía sobre tierras ancestrales, y a la consulta como mecanismo de interacción entre el Estado y pueblos indígenas (SAUL, 20I6).

\section{Los límites de la consulta en Chile:}

\section{el resurgimiento de la libre determinación}

El derecho internacional ha jugado durante el siglo XIX un rol importante en la consolidación de la soberanía de los Estados latinoamericanos en perjuicio de los pueblos originarios (BECKER Y ALVEZ). El lento pero significativo surgimiento durante el siglo $\mathrm{xx}$ de un derecho internacional de los pueblos indígenas, con el Convenio 169 y la Declaración de Naciones Unidas del 2007 como piezas centrales, ha marcado la transformación del derecho internacional en una herramienta útil en la lucha por el respeto de los derechos indígenas ante los Estados. Hemos visto que estos derechos pueden ser concebidos como derechos a la libre determinación interna, como derechos individuales y de grupo que gozan los indígenas dentro de los Estados, o concebidos como derecho a la libre determinación externa, a formar unidades políticas independientes de aquellos. Para bien o para mal, es la primera interpretación, por razones históricas y estratégicas, la que ha predominado en Latinoamérica.

Aún con este devenir, entrada la segunda década del presente siglo, se ha visto desde parte del movimiento indígena y el mundo indianista, el resurgimiento de la autodeterminación de corte independentista. Si ésta ha sido una tendencia regional, en Chile se ha expresado con vigor particular.

El derecho internacional de los pueblos indígenas llegó a Chile demasiado tarde y por ello probablemente demasiado débil. Mientras la promesa del derecho internacional como herramienta de lucha para los pueblos en vez de herramienta de legitimación para los Estados, persista sólo como promesa, los pueblos indígenas que existen dentro del territorio chileno estarán dispuestos a explorar avenidas de lucha alternativas. La renuencia de las autoridades chilenas de adoptar el Convenio I69, sino hasta el 2008, y la tardanza para implementar los mecanismos de consulta que ya establecía la Ley Indígena de 1993, sino hasta la ratificación del Convenio, significó 
que el derecho internacional de los pueblos indígenas llegó tarde a Chile ${ }^{12}$. Al tiempo que se introducía la consulta dentro de un marco de derecho a la participación, desde el mundo indígena las demandas habían ya mutado desde la participación a la autodeterminación. Este cambio se había producido antes, acorde a la tendencia regional desde el levantamiento de Chiapas (1994), pero también como resultado de la situación chilena, a partir de la crisis desencadenada por la construcción del embalse de Ralco por la generadora eléctrica ENDESA en el Alto Biobío (principio de los noventa), a pesar de la firme oposición de comuneros Mapuche-Pehuenche (MORAGA, 200I; NAMUNCURA, 1999) y a partir del incendio de camiones de la empresa Forestal Arauco en Lumaco (TRICOT, 20I2; PAIRICÁN Y ÁLVAREZ, 2OII: 66-84).

La opción autonomista se fortalecía no sólo del arribo tardío del régimen de protección internacional, sino también de la debilidad de éste en su incorporación en Chile. En tanto firmemente concebido como participación y diálogo multicultural con el fin de obtener consentimiento y lejos de un derecho a veto, la consulta dejaba en pie a las fuerzas económicas, principalmente del sector forestal, que compiten por tierras indígenas, dejando como interlocutores legítimos sólo a grupos indígenas dispuestos a participar en este marco, deslegitimizando y criminalizando a grupos que demandan libre determinación y derecho a veto en el proceso de consulta (BIDEGAIN, 2OI7; PAIRICÁN, 2OI4; RICHARDS, 2OI3). Mientras la renuencia del sistema político chileno a dar cabida a las demandas del movimiento indígena contribuye a la emergencia de posturas más autonomistas, en el plano de las ideas, es la obra del pensador José Marimán la que plasma la irrupción en la intelectualidad Mapuche de posturas autónomas etno-nacionalistas (MARIMÁN, 2OI2).

Sin embargo, debemos distinguir entre las dispares realidades y contextos históricos que informan la relación entre el Estado chileno y los pueblos Aimara, Atacameño, Colla, Kawésqar, Mapuche, Quechua, Rapa Nui y Yámana. ${ }^{13}$ El pueblo Mapuche, como el mayor de los pueblos originarios y en conjunto con el pueblo Rapa Nui, como pueblos que mantuvieron su independencia política hasta la expansión militar del Estado chileno del siglo XIX, marcan una trayectoria distintiva. Mientras en el territorio continental, los pueblos indígenas al norte del río Biobío, habían interactuado por siglos con las autoridades coloniales, al sur

12] Ley Indígena $n^{\circ} 19.253$ Establece Normas Sobre Protección, Fomento y Desarrollo de los Indígenas Ley $n^{\circ} 19.252$ (D. Of. 5.10.1993)

13] Considerando sólo los pueblos reconocidos por la Ley Indígena, Ley nº 19.252. 
de la frontera el pueblo Mapuche había mantenido independencia y coexistencia política mediante la fuerza y la celebración de tratados con la corona española. La memoria histórica de independencia junto al rol simbólico que cumplían los tratados, hacen de los Mapuche y Rapa Nui pueblos que se asemejan más a los pueblos originarios del norte global que abogaban por libre determinación, que a los pueblos indígenas del sur global que, como hemos visto, abogaban por participación. Es decir, las trayectorias de los pueblos Mapuche y Rapa Nui calzan mejor en la trayectoria de los pueblos que han históricamente demandado libre determinación, en su dimensión externa, e incluso durante las negociaciones que llevaron a la institución del derecho internacional de los pueblos indígenas.

En el caso Mapuche, la larga historia diplomática, desde los tiempos del arribo español hasta la independencia y el período contemporáneo, en que por medio de un sinnúmero de parlamentos el pueblo ha negociado su relación con autoridades foráneas, muestra la persistencia de la demanda de coexistencia (PAIRICÁN, HUENCHUNAO Y LLAITUL, 20I6). Las tensiones en esta trayectoria se vieron exacerbadas por la crisis entre Estado chileno y pueblo Mapuche a fines de los noventa (PAIRICÁN, 2OI4; RICHARDS, 2OI3). La vibrante tradición intelectual Mapuche giró entonces definitivamente hacia la libre determinación, si se contrastan por ejemplo las posturas de organizaciones de mediados del siglo xx, como la Federación Araucana, presidida por Manuel Aburto Panguilef, y las posturas de la CAM hacia fines de siglo (PANGUILEF y MENARD, 2OI3; MARIMÁN, 2OI2). ¿Cuál es el rol que le cabe al derecho internacional de los pueblos indígenas frente al conflicto entre pueblo Mapuche y Estado chileno, una vez que este pueblo ha transitado hacia demandas de autodeterminación ya no etnicista, sino etno-nacional?

\section{CONCLUSIÓN}

Desde un punto de vista de derecho internacional formal, no hay dudas: la consulta previa, obligatoria respecto de Chile como firmante del Convenio I69, otorga a los pueblos indígenas derechos de participación en los procesos de decisión pública. Superar una implementación lenta, parcial y formalista de la consulta indígena, a fin de convertirla en una herramienta efectiva de participación democrática, representaría un avance significativo para los pueblos indígenas en Chile (Cut y ObSERVATORIo CIUDAdano, 20I8). Si la consulta indígena como dispositivo 
de participación democrática inserto en la estructura estatal chilena es suficiente para procesar las demandas de un pueblo como el Mapuche, que ha transitado hacia demandas de autonomía y libre determinación, deberá verse una vez que la consulta sea implementada a profundidad, esto es, cuando la consulta busque la obtención de un consentimiento previo, libre e informado, reconociendo la posibilidad de un veto indígena hoy inexistente.

Mientras la consulta no sea seriamente implementada, son los mismos déficits del régimen legal chileno que empujan al movimiento Mapuche hacia avenidas políticas y legales alternativas. En este caso, desde un punto de vista de derecho internacional formal, tampoco hay dudas. El derecho internacional no reconoce a los pueblos originarios derechos de libre determinación y así los límites de la consulta coinciden con los límites de los DD.HH. Los pueblos indígenas gozan de derechos en tanto se encuentran sujetos a la jurisdicción del Estado. Pero el Estado limita el ejercicio de su soberanía, reconociendo la obligación de consultar, como derecho especial de participación (ANAYA Y PUIG, 20I7: 435-464). Que el Estado, en cuanto soberano, imponga límites a su soberanía no en tanto a su ejercicio con respeto a los DD.HH., sino en tanto a su alcance frente a una potencial sesión de autonomía, depende no de una obligación legal, sino de los desenlaces de un conflicto político. Es aquí donde, mientras desde un punto de vista de derecho formal la situación es clara, desde un punto de vista político, es incierta.

El derecho internacional, si bien en abstracto niega el derecho de libre determinación a pueblos indígenas, deja la puerta abierta a que mientras el conflicto no se resuelva por medios pacíficos, la represión estatal vulnere el derecho de libre determinación interna de Mapuches en tanto chilenos que gozan de este derecho como derecho humano (MACKLEM, 2015: Cap. 6 y 7) ${ }^{14}$. Cuando la libre determinación interna del pueblo Mapuche no pueda ser ejercida substancial y significativamente - incluyendo el cúmulo de derechos civiles y políticos, económicos, sociales y culturales, y derechos indígenas - entonces el derecho de libre determinación externa, como grupo que reclama autonomía frente a la vulneración de derechos fundamentales por parte del Estado chileno, puede ser gatillado. Y en este caso el derecho internacional ya no ofrece sólo una plataforma para la resolución pacífica, sino regulación en el caso de conflicto armado generalizado.

14] Recuérdese que el derecho a la libre determinación es un derecho humano básico reconocido por ambos Pactos de Derechos Humanos. Véase Macklem. 
Mientras la represión y negación de derechos del pueblo Mapuche aumente, los argumentos a favor de una «secesión correctiva» [remedial secession] (como medio para remediar esta vulneración de derechos) serán aún más fuertes. De ocurrir aquello, el derecho internacional ofrece legitimidad a la lucha del pueblo Mapuche, en un conflicto ahora caracterizado como de liberación nacional. Y ofrece además regulación, con las normas de derecho internacional humanitario aplicable a conflictos no-internacionales y a conflictos de liberación nacional. Aquí vemos finalmente el rol fundamental que cumple la consulta indígena como parte del compromiso entre participación y autonomía.

Mientras la consulta se acerque más a la autonomía y a la libre determinación interna, paradojalmente, debilita el argumento para aplicar la libre determinación externa. Pero si autoridades chilenas continúan evadiendo la implementación profunda de la consulta indígena, podrán haber contribuido a transformar los derechos de participación del pueblo Mapuche, en derechos de libre determinación.

\section{Referencias bibliográficas}

ANAYA, JAMES (2004): Indigenous peoples in international law. USA, Oxford University Press.

ANAYA, JAMES (2004b): «El derecho de los pueblos indígenas a la libre determinación tras la adopción de la Declaración», en: Chambers, Claire y Stavenhagen, Rodolfo (Eds.) El Desafío de la Declaración: historia y futuro de la Declaración de la ONU sobre pueblos indígenas. Copenhague: IWGIA, pp. 194-209.

ANAYA, JAMES (2008): «Report of the Special Rapporteur on the situation of human rights and fundamental freedoms of indigenous people» UN Doc A/HRC/9/9 2008.

ANAYA, S. JAMES Y PUIG, SERGI0 (2017): «Mitigating state sovereignty: The duty to consult with indigenous peoples», en: University of Toronto Law Journal, no 67. 4, pp. 435-464.

BECKER LORCA, ARNULF Y ALVEZ MARIN, AMAYA: «EI Derecho Internacional en contra de los Pueblos Indígenas de América Latina", manuscrito inédito. BARELLI, MAURO (2016): Seeking justice in international law: the significance and implications of the UN Declaration on the Rights of Indigenous Peoples, Routledge.

BELLIER, IRENE (2010): «La participación de los pueblos indígenas en la Organización de las $\mathrm{Na}$ - 
ciones Unidas: construcción de una voz indígena y producción de normas», en: Brett, Roddy y Santamaría, Ángela (Eds.) Jano y las caras opuestas de los derechos humanos. Bogotá, Editorial Universidad del Rosario, pp. 41-71.

BIDEGAIN, GERMÁN (2017): «From Cooperation to Confrontation: The Mapuche Movement and Its Political Impact, 1990-2014» en: Donoso, S., von Bülow, M. (eds.), Social Movements in Chile, Palgrave Macmillan, New York.

CARMONA, CRISTÓBAL (2013): «Tomando los derechos colectivos en serio: el derecho a consulta previa del Convenio 169 de la OIT y las instituciones representativas de los pueblos indígenas», en: Revista lus et Praxis, n 19.2, pp. 301-334. CASTRO, MILKA (Investigadora responsable) (2018): Sistematización y análisis de experiencias del ejercicio del derecho de consulta previa desde la institucionalidad en Chile, Estudio Ministerio Desarrollo Social - Universidad de Chile, Facultad de Derecho.

CENTRAL UNITARIA DE TRABAJADORES-OBSERVATORIO CIUDADANO (2018): El Convenio 169 de la OIT sobre Pueblos Indígenas y Tribales a 10 años de su ratificación por el estado de Chile: análisis crítico de su cumplimiento. Temuco.

ENGLE, KAREN (2010): The elusive promise of indigenous development: Rights, culture, strategy, Duke University Press.

ENGLE, KAREN (2011): «On Fragile Architecture: The UN Declaration on the Rights of Indigenous Peoples in the Context of Human Rights», en: European Journal of International Law, vol. 22.1. ESCÁRZAGA, FABIOLA (2012): «Comunidad indígena y revolución en Bolivia: el pensamiento indianista-katarista de Fausto Reinaga y Felipe Quispe», en: Política y cultura, n³7, pp. 185-210. ERUETI, ANDREW (2016): The UN Declaration on the Rights of Indigenous Peoples: A Mixed-Model
Interpretative Approach, tesis doctoral, Toronto University.

ERUETI, ANDREW (2017): «The politics of international indigenous rights», University of Toronto Law Journal, n67.4, pp. 569-595.

GUERRA-SCHLEEF, FELIPE (2017): «Los Tribunales Ambientales en la implementación de los derechos indígenas durante la evaluación ambiental de proyectos de inversión en Chile», en: Revista Justicia Ambiental, n 9, pp. 19-38.

IL0 (1989): Provisional Record, Seventy-sixth Session, Geneva, Resolución 25/1.

KENNEDY, DAVID (1987): International legal structures, Nomos-Verlag-Ges.

LÂM, MAIVÂN (2000): At the Edge of the State: Indigenous Peoples and Self Determination, Brill Nijhoff.

MACKLEM, PATRICK MACKLEM (2015): The sovereignty of human rights, Londres, Oxford University Press. MARIMÁN, JOSÉ (2012): Autodeterminación: Ideas políticas mapuche en el albor del siglo XXI, Santiago, Lom Ediciones.

MARTINEZ COBO, JOSÉ (1983): «Study of the problem of discrimination against indigenous populations: final report (last part)», UN Doc E/CN.4/ Sub.2/1983/21/Add.8

MARTINEZ COBO, JOSÉ (1986): «Study of the problem of discrimination against indigenous populations, vol. 1, UN Doc E/CN.4/Sub.2/1986/7

MEZA-LOPEHANDÍA, MATÍAS (2016): «La jurisprudencia del multiculturalismo en Chile: La consulta previa indígena ante tribunales», en: Revista de Ciencias Sociales, $\mathrm{n}^{\circ} 69$.

MEZA-LOPEHANDÍA, MATÍAS (2018): «Frustrated Multiculturalism: (Neo)Liberalism and the Mapuche People», en: Marshall, Pablo (Ed.). Citizenship and Disadvantaged Groups in Chile. Lexington Books.

MILLALÉN PAILLAL, JOSÉ (2013): «Taiñ mapuchegen. 
Nación y nacionalismo Mapuche: construcción y desafío del presente», en: Ta iñ fike xipa rakizuameluwün. Historia, colonialismo y resistencia desde el país Mapuche, Temuco, Ediciones Comunidad de Historia Mapuche, pp. 235-251. MORAGA, JORGE (2001): Aguas turbias: la central hidroeléctrica Ralco en el Alto Biobío, Observatorio Latinoamericano de Conflictos Ambientales, Santiago, Lom Ediciones.

MORRIS, MEGHAN, RODRÍGUEZ, CÉSAR, ORDUZ, N. Y BURITICÁ, PAULA (2009): "La consulta previa a pueblos indígenas: los estándares del derecho internacional», documento $n^{\circ} 2$, Programa de Justicia Global y Derechos Humanos, pp. 1-52. MOYN, SAMUEL (2012): The last utopia, Harvard University Press.

NAMUNCURA, DOMINGO (1999): Ralco, irepresa o pobreza?, Santiago, Lom Ediciones.

NUÑEZ POBLETE, MANUEL (2014): «La consulta indígena en el procedimiento de calificación ambiental. Desarrollo reglamentario y configuración judicial», en: Anuario de Derecho Público, nº 1, pp. 317-338.

ONU, Asamblea General (2007): Declaración sobre los derechos de los pueblos indígenas.

PAIRICÁN, FERNANDO Y ÁLVAREZ, ROLANDO (2011): «La Nueva Guerra de Arauco: La Coordinadora Arauco Malleco en el Chile de la Concertación de Partidos por la Democracia (1997-2009)», en: Revista www.izquierdas.cl, $\mathrm{n}^{\circ} 10$, agosto.

PAIRICÁN, FERNANDO (2014): Malón: La rebelión del movimiento mapuche, 1990-2013, San- tiago, Editorial Pehuén, Pensamiento mapuche contemporáneo.

PAIRICÁN, FERNANDO, HUENCHUNAO, JOSÉ Y LLAITUL CARRILLANCA, HÉCTOR (2016): Pueblo mapuche y autodeterminación, Le Monde diplomatique.

PANGUILEF, MANUEL ABURTO Y MENARD, ANDRÉ (2013): Libro diario del Presidente de la Federación Araucana: 1940, 1942, 1948-1951, CoLibris. RICHARDS, PATRICIA (2013): Race and the Chilean miracle: Neoliberalism, democracy, and indigenous rights, University of Pittsburgh Press. SANHUEZA CUBILLOS, CRISTIÁN (2013): «La Consulta Previa en Chile: del dicho al hecho», en: Derecho y Pueblo Mapuche. Aportes para la discusión, Centro de Derechos Humanos de la Universidad Diego Portales, Chile.

SAUL, BEN (2016): Indigenous Peoples and human rights: International and regional jurisprudence, Bloomsbury Publishing.

STAVENHAGEN, RODOLFO (2011): «How strong Are the rights of indigenous peoples? ", en: Journal of Human Rights, vol. 10, pp. 414-421.

TRICOT, TIT0 (2012): Autonomía. El movimiento Mapuche de resistencia. Editorial CEIBO.

WILLIAMS JR, ROBERT A (1990): «Encounters on the Frontiers of International Human Rights Law: Redefining the Terms of Indigenous Peoples' Survival in the World", en: Duke University Law Journal, n4, pp. 660-704.

XANTHAKI, ALEXANDRA (2007): Indigenous rights and United Nations standards: self-determination, culture and land, Cambridge University Press. 